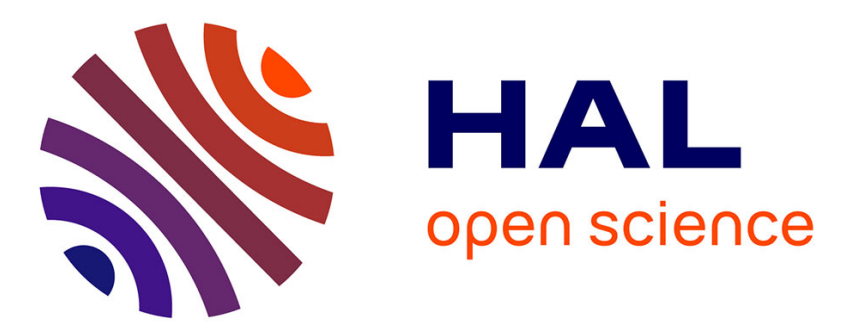

\title{
A chiral uranyl-Kemp's tricarboxylate cubic framework: structure-directing effect of counterions with three-fold rotational symmetry
}

Pierre Thuéry, Jack Harrowfield

\section{- To cite this version:}

Pierre Thuéry, Jack Harrowfield. A chiral uranyl-Kemp's tricarboxylate cubic framework: structuredirecting effect of counterions with three-fold rotational symmetry. Dalton Transactions, In press, 50, pp.11021-11024. 10.1039/D1DT02232F . cea-03320580

HAL Id: cea-03320580

https://hal-cea.archives-ouvertes.fr/cea-03320580

Submitted on 16 Aug 2021

HAL is a multi-disciplinary open access archive for the deposit and dissemination of scientific research documents, whether they are published or not. The documents may come from teaching and research institutions in France or abroad, or from public or private research centers.
L'archive ouverte pluridisciplinaire $\mathbf{H A L}$, est destinée au dépôt et à la diffusion de documents scientifiques de niveau recherche, publiés ou non, émanant des établissements d'enseignement et de recherche français ou étrangers, des laboratoires publics ou privés. 


\title{
A chiral uranyl-Kemp's tricarboxylate cubic framework: structure- directing effect of counterions with three-fold rotational symmetry $\dagger$
}

\author{
Pierre Thuéry*a and Jack Harrowfield*b
}

In the presence of $\mathrm{PPh}_{3} \mathrm{Me}^{+}$cations, Kemp's tricarboxylate ( $\left.\mathrm{kta}^{3-}\right)$ complexes the uranyl cation to give $\left[\mathrm{PPh}_{3} \mathrm{Me}\right]\left[\mathrm{UO}_{2}(\mathrm{kta})\right](\mathbf{1})$, a triperiodic framework with cubic symmetry and srs topology. The cation is held by weak interactions into cavities with matching threefold rotational symmetry. Comparison with the diperiodic hemihydrate polymorph previously reported points to the disrupting role of $\mathrm{OH} \cdots \mathrm{O}$ hydrogen bonds in the latter.

Among the extremely varied carboxylate-containing ligands which have been used to generate uranyl-based coordination polymers and frameworks, ${ }^{1}$ the tricarboxylate derived from Kemp's triacid, cis, cis1,3,5-trimethylcyclohexane-1,3,5-tricarboxylic acid ( $\left.\mathrm{H}_{3} \mathrm{kta}\right)$, is particularly appealing, having given several metallacyclic rings, cages and nanotubular complexes, besides more usual mono- and diperiodic polymers. ${ }^{2}$ The most conspicuous absence in the series of complexes so far obtained is that of triperiodic frameworks. Adoption of a chair conformation of its six-membered ring by $\mathrm{kta}^{3-}$ provides a ligand of three-fold rotational symmetry which, in the conformation where the carboxylate groups are equatorially oriented, appears ideally suited to the formation of crystals with a diperiodic uranyl ion complex array of honeycomb (hcb) topology where the uranyl ion centres have a hexagonal-bipyramidal $\mathrm{UO}_{2}\left(\kappa^{2} O, O^{\prime} \text {-carboxylate }\right)_{3}$ form. In contrast, the convergent, chair triaxial form of the ligand favours the formation of oligomeric closed species. Several honeycomb networks have also been found with the ligand in the boat diequatorial, monoaxial conformation, ${ }^{2 c-e}$ and the hcb topology is thus the most common in uranyl complexes with this ligand. In the $1: 1 \quad \mathrm{UO}_{2}{ }^{2+} / \mathrm{kta}^{3-}$ stoichiometry found in these networks, the complex is anionic and therefore must be accompanied by a countercation which is of course another influence within the structure. For structure-directing species incapable of direct coordination to carboxylate groups, their hydrogen bonding capacity appears to have a strong influence upon the form of their associated $\left[\mathrm{UO}_{2}(\mathrm{kta})\right]^{-}$species, so that the present isolation of anhydrous $\left[\mathrm{PPh}_{3} \mathrm{Me}\right]\left[\mathrm{UO}_{2}(\mathrm{kta})\right](\mathbf{1})$ has, by comparison to its

a Université Paris-Saclay, CEA, CNRS, NIMBE, 91191 Gif-sur-Yvette, France; E-mail: pierre.thuery@cea.fr

${ }^{b}$ Université de Strasbourg, ISIS, 8 allée Gaspard Monge, 67083 Strasbourg, France; E-mail: harrowfield@unistra.fr

$\dagger$ Electronic supplementary information (ESI) available: Experimental details, Figs. S1-S5. CCDC 2091685. For ESI and crystallographic data in CIF or other electronic format see DOI: previously characterized hemi-hydrate $(2),{ }^{2 e}$ provided an opportunity to assess the influence of strong $(\mathrm{OH})$ and weak $(\mathrm{CH})$ hydrogen bond donors upon the structure of the associated anionic metallapolymer. It is of course expected that the inherent difference between $\mathrm{OH} \cdots \mathrm{O}$ and $\mathrm{CH}$.. O interactions should be large but numerical factors do also need to be taken into account. In the event, the differences between the two structures are striking. Further, the differences between the two unsolvated compounds $\mathbf{1}$ and $\left[\mathrm{PPh}_{4}\right]\left[\mathrm{UO}_{2}(\mathrm{kta})\right](\mathbf{3})^{2 e}$ are equally striking and provide some indication of the finer detail involved in aliphatic and aromatic $\mathrm{CH} \cdots \mathrm{O}$ interactions.

The complex $\left[\mathrm{PPh}_{3} \mathrm{Me}\right]\left[\mathrm{UO}_{2}(\mathrm{kta})\right]$ (1) was synthesized ${ }^{\ddagger}$ under solvo-hydrothermal conditions similar to those giving complex $\mathbf{2}$, but for the addition of neodymium nitrate hexahydrate, intended to provide a heterometallic complex but eventually not included in the final product. Although difficult to rationalize, since nothing is known of the solution equilibria which may influence the solubility of any particular species, the effect of this modification in the synthetic conditions on the crystal structure is considerable, notwithstanding the fact that the formulas of $\mathbf{1}$ and $\mathbf{2}$ differ by only half a solvent water molecule.

Complex 1 crystallizes in the Sohncke ${ }^{3}$ cubic space group $P 213, \S$ with the uranium atom, located on a three-fold rotation axis (Wyckoff position $4 a$ ), in a hexagonal-bipyramidal environment (Figure 1) and it provides a not uncommon example of a uranyl-carboxylate polymer forming a chiral crystal. The $\mathrm{kta}^{3-}$ ligand, in the chair, triequatorial conformation, has also three-fold rotational symmetry and its three carboxylate groups are $\kappa^{2} O, O^{\prime}$-chelating. It is notable that the carboxylate groups are much closer to perpendicular to the mean plane of the ring than in $\mathbf{2}$ and $\mathbf{3}$ [dihedral angles $76.03(12)^{\circ}$ in $\mathbf{1}$ versus 24.4(3)-40.7(2) ${ }^{\circ}$ in 2, and 21.5(8)-64.4(3) ${ }^{\circ}$ in 3; Figure S1], the shape of the ligand being thus farther from discoidal. Despite the fact that both metal and ligand are three-coordinated (3-c) nodes as in the hcb networks previously reported, notably in $2,^{2 e}$ the uninodal coordination polymer formed is here triperiodic and it has the point symbol $\left\{10^{3}\right\}$ and the srs $\left(\mathrm{SrSi}_{2}\right)$ topological type ${ }^{4}$ (Figures $2 \mathrm{a}$ and $\mathrm{S} 2$ ). This common topology has previously been found in uranyl complexes with glutarate ${ }^{5}$ or cis-1,4-cyclohexanedicarboxylate, ${ }^{6}$ with uranium atoms only as 3-c nodes. The srs net is one of the basic 3-c triperiodic nets (while the hcb net is the simplest 3-c diperiodic net) and it is noted to be the only one with vertices having three-fold rotational symmetry. ${ }^{4}$ Although this topology frequently leads to interpenetration of enantiomorphic nets, this is prevented here by the 
bulky $\mathrm{PPh}_{3} \mathrm{Me}^{+}$cations which occupy all available spaces, the Kitaigorodski packing index given by PLATON ${ }^{7}$ being $0.71(0.35$ with cations excluded). The cations are nestled within cavities centered on the three-fold axes (Figures $2 b$ and S3), which entails $\mathrm{CH} \cdots \mathrm{O}$ hydrogen bonds involving the cation methyl group and three carboxylate oxygen atoms $\left[\mathrm{C} \cdots \mathrm{O}, 3.318(2) \AA ; \mathrm{C}-\mathrm{H} \cdots \mathrm{O}, 158^{\circ}\right]$ or aromatic protons and oxo groups, as well as $\mathrm{CH}(\mathrm{kta}) \cdots \pi$ interactions. The interactions between the methyl group of the cation and three

a

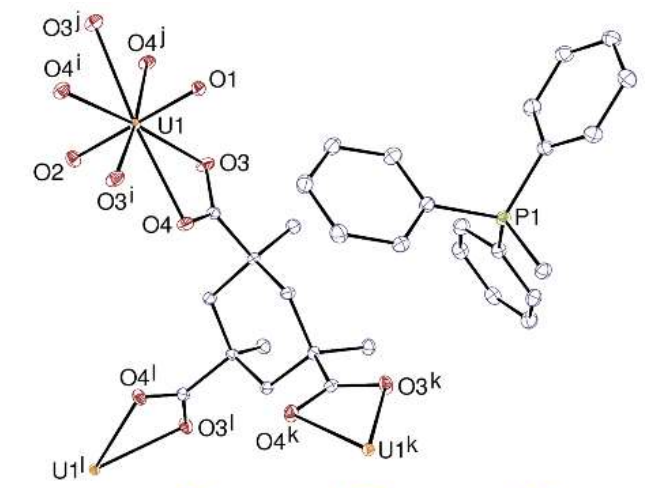

b

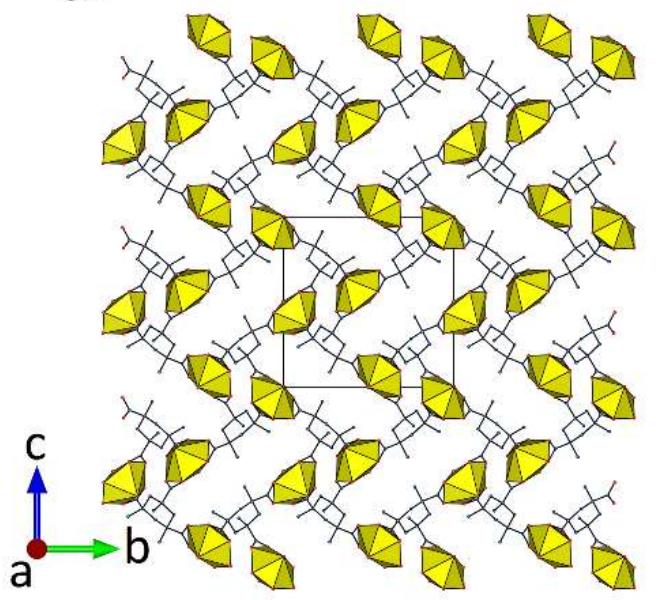

C

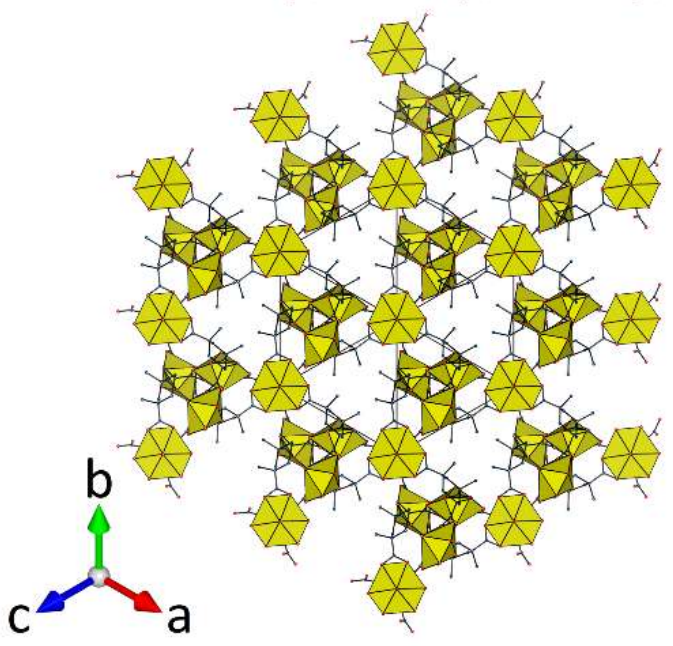

Fig. 1 (a) View of complex 1. Displacement ellipsoids are drawn at the $50 \%$ probability level and hydrogen atoms are omitted. Symmetry codes: $\mathrm{i}=y+$ $1 / 2,1 / 2-z, 1-x ; \mathrm{j}=1-z, x-1 / 2,1 / 2-y ; \mathrm{k}=y, z, x ; 1=z, x, y$. Selected bond lengths $(\AA)$ and angles $\left({ }^{\circ}\right)$ : U1-O1 1.779(3), U1-O2 1.781(3), U1-O3 2.4498(14), U1-O4 2.4757(15), O1-U1-O2 180, O3-U1-O4 52.69(5), O4U1-O3 $3^{\mathrm{i}}$ 67.59(5). (b) and (c) Two views of the framework, down [100] or [111] (parallel to the $C_{3}$ axis), with uranium coordination polyhedra colored yellow and counterions omitted.

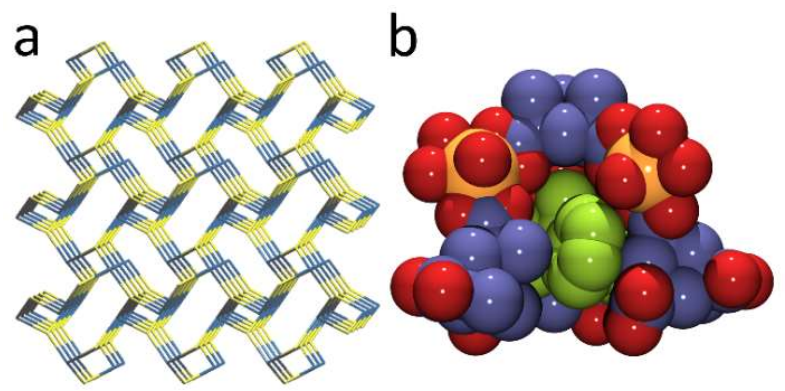

Fig. 2 (a) Nodal representation of the framework with srs topology in $\mathbf{1}$ down a direction slightly rotated from [100] (yellow, uranium nodes; blue, ligand nodes). (b) Space filling representation of the inclusion of the $\mathrm{PPh}_{3} \mathrm{Me}^{+}$cation within the cavity centered on the three-fold rotation axis. Yellow, uranium; red, oxygen; blue, carbon in $\mathrm{kta}^{3-}$; green, all atoms of the counterion. Hydrogen atoms are omitted.

carboxylate groups, in particular, are related to the tilting of the latter with respect to the mean cyclohexyl plane. There is no direct interaction between the $\mathrm{PPh}_{3} \mathrm{Me}^{+}$cations, all $\mathrm{P} \ldots \mathrm{P}$ distances being larger than $9.8 \AA$. Although diperiodic uranyl polymer sheets orthogonal to [111] involving fused, 72-membered clover-shaped nona-uranacycles (Figure S4) can be discerned, only three of the nine equatorial $\mathrm{UO}_{6}$ entities in a given ring lie parallel to this plane, the others being involved in coordination providing crosslinks to sheets above and below to give the full triperiodic array.

While in solution both $\mathrm{kta}^{3-}$ and $\mathrm{PPh}_{3} \mathrm{Me}^{+}$appear, on the basis of their ${ }^{1} \mathrm{H}$ NMR spectra, ${ }^{8}$ to have $C_{3 v}$ symmetry, motional restrictions in the solid state can reduce this symmetry to $C_{3}$ and this is the case in the crystal of $\mathbf{1}$. For $\mathrm{kta}^{3-}$, this is due to the fact that the OCO planes of the carboxylate groups are tilted in the same sense with respect to the mean plane of the cyclohexane ring (Figure S5), the $\mathrm{O} \cdots \mathrm{O}$ segments defining a left-handed helical array about the $C_{3}$ axis in the case of the particular crystal studied. In this same crystal, the cation also shows $C_{3}$ symmetry but here the $\mathrm{C} \cdots \mathrm{C}$ vectors shown in Figure S5 define a right-handed helical array about the axis. While $\mathrm{PPh}_{3} \mathrm{Me}^{+}$ in $\mathbf{2}$ is chiral and has a conformation close to one of $C_{3}$ symmetry, the $\mathrm{kta}^{3-}$ ligand has a symmetry close to $C_{3 v}$ and the complete crystal is achiral (space group $P b c a$ ). In this case, the three-fold symmetry of the cation is not reflected in its interactions beyond dispersion, a difference evident on the Hirshfeld surfaces generated with CrystalExplorer ${ }^{9}$, shown in Figure 3. These interactions of an unsymmetrical nature involve here also $\mathrm{CH} \cdots \mathrm{O}$ hydrogen bonds between the cation methyl group and carboxylate oxygen atoms or between aromatic protons and oxo or carboxylate groups, as well as
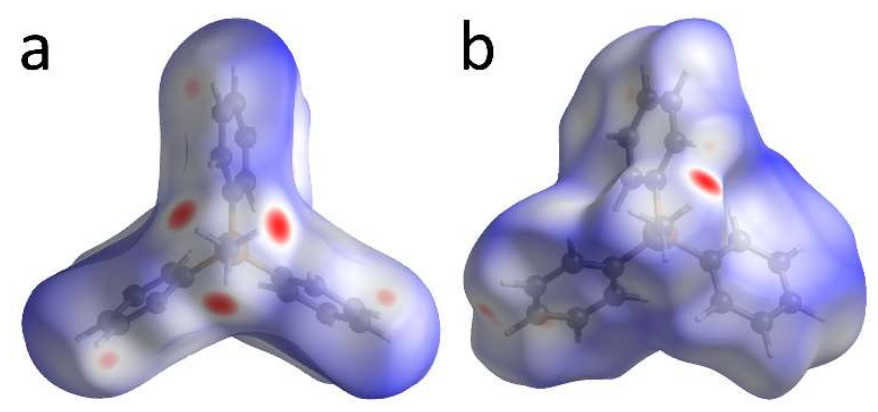

Fig. 3 Hirshfeld surface of the $\mathrm{PPh}_{3} \mathrm{Me}^{+}$cation mapped with $d_{\text {norm }}$ in complexes 1 (a) and 2 (b) viewed down the $\mathrm{P}-\mathrm{CH}_{3}$ bond. The red spots near the methyl group correspond to $\mathrm{CH} \cdots \mathrm{O}$ hydrogen bonds. 
$\mathrm{CH}(\mathrm{kta}) \cdots \pi$ interactions. The result is that each cation is associated with three $\left[\mathrm{UO}_{2}(\mathrm{kta})\right]^{-}$units, each one in a different way, rather than six, in three symmetric pairs, as in $\mathbf{1}$. This perturbation of the interactions with respect to those in the anhydrous crystal is seemingly associated with the presence in $\mathbf{2}$ of the water molecule which bridges, through hydrogen bond donation, two carboxylate oxygen atoms on every second uranyl centre. Interestingly, this presumably strong hydrogen bonding does not appear to inhibit further $\mathrm{CH}$-donation to the same two carboxylate oxygen atoms. "Symmetry matching" of the components of a solid is clearly seen in the structure of $\mathbf{1}$ to be a significant influence on that structure, but its operation there passes through weak interactions which are not of a unique nature and can readily accommodate minor variations in the components of a crystal. The striking difference in structure between $\mathbf{1}$ and its hemi-hydrate $\mathbf{2}$ thus seems to have rather subtle origins, disruption of the symmetric interactions found in $\mathbf{1}$ by the additional water molecule in $\mathbf{2}$ being possibly a major influence.

The $\mathrm{PPh}_{4}{ }^{+}$cation in $\mathbf{3}$ has an irregular chiral form and while it can in principle adopt a propeller form, this cannot have $C_{3}$ symmetry (except if one aromatic ring is disordered), so that the ordered cation is symmetrically "incompatible" with any three-fold-symmetric form of the kta ${ }^{3-}$ ligand, which in fact in $\mathbf{3}$ has a conformation close to one with a plane of symmetry $\left(C_{\mathrm{s}}\right)$, meaning that here the chirality of the crystal (space group $P 2_{1}$ ) is a reflection of that of the cation. Interactions beyond dispersion of the countercation with the hcb diperiodic polymer involve several $\mathrm{CH}$... O hydrogen bonds between aromatic protons and oxo or carboxylate groups making a rather different pattern to those seen for the other two complexes. It is noteworthy that formation of the hcb form of $\left[\mathrm{UO}_{2}(\mathrm{kta})\right]^{-}$does not require the presence of counterions with three-fold rotational symmetry and the network can be considerably distorted with respect to this ideal symmetry, in particular when $\mathrm{kta}^{3-}$ adopts the boat conformation..$^{2 e}$ Being observed with counterions very different from one another, ${ }^{2 e}$ the hcb topology may reflect a genuine preference of the uranyl ion for complexation in planar arrays. Complexes $\mathbf{1}$ and $\mathbf{3}$ provide examples of the class of chiral crystals generated not from chiral components but from configurationally labile species which can adopt chiral forms not separately observable in solution.

Although the triaxial form of the anions of Kemp's triacid in the chair conformation is particularly prone to give closed, polynuclear complexes with uranyl ions, ${ }^{2 e} \mathbf{h c b}$ diperiodic networks are the most common species of coordination polymer found with the triequatorial form. Complex $\mathbf{1}$ is the first example of a triperiodic framework obtained in this family, and it has the srs topology which retains the three-fold rotational symmetry of the ideal hcb net. The transition from the srs network in $\mathbf{1}$ to the hcb in the hemi-hydrate $\mathbf{2}$ is accompanied by a disruption of the three-fold symmetric weak interactions between polymer and counterions seen in $\mathbf{1}$ by the hydrogen bonded water molecule in 2 . While multiple weak $(\mathrm{CH} \cdots \mathrm{O})$ interactions can provide an efficient means for the transmission of chirality from one component to another, the apparently subtle compositional variation associated with conversion from an anhydrous material to a hemi-solvate has dramatic consequences indicative of the dominance of classical over weak hydrogen bonding.

\section{Conflicts of interest}

There are no conflicts of interest to declare.

\section{Notes and References}

$\ddagger$ Synthesis of complex 1. $\mathrm{H}_{3} \mathrm{kta}(13 \mathrm{mg}, 0.05 \mathrm{mmol})$, $\left[\mathrm{UO}_{2}\left(\mathrm{NO}_{3}\right)_{2}\left(\mathrm{H}_{2} \mathrm{O}\right)_{2}\right] \cdot 4 \mathrm{H}_{2} \mathrm{O}(25 \mathrm{mg}, 0.05 \mathrm{mmol}),\left[\mathrm{Nd}\left(\mathrm{NO}_{3}\right)_{3}\right] \cdot 6 \mathrm{H}_{2} \mathrm{O}$ (22 mg, $0.05 \mathrm{mmol}), \mathrm{PPh}_{3} \mathrm{MeBr}(18 \mathrm{mg}, 0.05 \mathrm{mmol}), N, N-$ dimethylformamide $(0.2 \mathrm{~mL})$, and demineralized water $(0.6 \mathrm{~mL})$ were placed in a $10 \mathrm{~mL}$ tightly closed glass vessel and heated at $140{ }^{\circ} \mathrm{C}$ under autogenous pressure in a sand bath, giving a few light yellow crystals of complex 1 within one week.

$\S$ The data were collected at $100(2) \mathrm{K}$ on a Bruker D8 Quest diffractometer using an Incoatec Microfocus Source $(\mathrm{I} \mu \mathrm{S} 3.0 \mathrm{Mo})$ and a PHOTON III area detector, and operated with APEX3. ${ }^{10}$ The data were processed with SAINT, ${ }^{11}$ and empirical absorption corrections were made with SADABS. ${ }^{12}$ The structure was solved by intrinsic phasing with SHELXT, ${ }^{13}$ and refined by full-matrix least-squares on $F^{2}$ with SHELXL, ${ }^{14}$ using the ShelXle interface. ${ }^{15}$ Drawings were made with ORTEP- $3^{16}$ and VESTA,${ }^{17}$ and the topological analysis with ToposPro. ${ }^{18}$ Crystal data for 1 : $\mathrm{C}_{31} \mathrm{H}_{33} \mathrm{O}_{8} \mathrm{PU}, M=802.57$, cubic, space group $P 213, a=14.2093(8) \AA, V=2868.9(5) \AA^{3}, Z=4$. Refinement of 127 parameters on 2929 independent reflections out of 106653 measured reflections $\left(R_{\text {int }}=0.053\right)$ led to $R 1=0.010, w R 2=$ $0.025, \Delta \rho_{\min }=-0.39, \Delta \rho_{\max }=0.50 \mathrm{e} \AA^{-3}$, Flack parameter $=0.000(4)$.

1 (a) M. B. Andrews and C. L. Cahill, Chem. Rev., 2013, 113, 1121; (b) T. Loiseau, I. Mihalcea, N. Henry and C. Volkringer, Coord. Chem. Rev., 2014, 266-267, 69; (c) J. Su and J. S. Chen, Struct. Bond., 2015, 163, 265; (d) P. Thuéry and J. Harrowfield, Dalton Trans., 2017, 46, 13660.

2 (a) P. Thuéry, Cryst. Growth Des., 2014, 14, 901; (b) P. Thuéry, Cryst. Growth Des., 2014, 14, 2665; (c) P. Thuéry and J. Harrowfield, Polyhedron, 2015, 98, 5; (d) J. Harrowfield and P. Thuéry, Eur. J. Inorg. Chem., 2020, 749; (e) P. Thuéry and J. Harrowfield, Inorg. Chem., 2021 60, 1683.

3 M. Nespolo, M. I. Aroyo and B. Souvignier, J. Appl. Crystallogr., 2018, 51, 1481.

4 (a) M. O'Keeffe, M. Eddaoudi, H. Li, T. Reineke, O. M. Yaghi, J. Solid State Chem., 2000, 152, 3; (b) O. Delgado Friedrichs, M. O'Keeffe and O. M. Yaghi, Acta Crystallogr., Sect. A, 2003, 59, 22; (c) S. T. Hyde, M. O'Keeffe and D. M. Proserpio, Angew. Chem. Int. Ed., 2008, 47, 7996.

5 R. A. Zehnder, J. M. Boncella, J. N. Cross, S. A. Kozimor, M. J. Monreal, H. S. La Pierre, B. L. Scott, A. M. Tondreau and M. Zeller, Cryst. Growth Des., 2017, 17, 5568.

6 P. Thuéry and J. Harrowfield, Inorg. Chem., 2017, 56, 13464.

7 A. L. Spek, Acta Crystallogr., Sect. D, 2009, 65, 148.

8 (a) D. S. Kemp and K. S. Petrakis, J. Org. Chem., 1981, 46, 5140; (b) https://www.chemicalbook.com/SpectrumEN_1779-493_1HNMR.htm.

9 S. K. Wolff, D. J. Grimwood, J. J. McKinnon, M. J. Turner, D. Jayatilaka and M. A. Spackman, CrystalExplorer 3.1, University of Western Australia, 2012.

10 APEX3, ver. 2019.1-0; Bruker AXS: Madison, WI, 2019.

11 SAINT, ver. 8.40A; Bruker Nano: Madison, WI, 2019.

12 SADABS, ver. 2016/2; Bruker AXS: Madison, WI, 2016.

13 G. M. Sheldrick, Acta Crystallogr., Sect. A, 2015, 71, 3.

14 G. M. Sheldrick, Acta Crystallogr., Sect. C, 2015, 71, 3.

15 C. B. Hübschle, G. M. Sheldrick and B. Dittrich, J. Appl. Crystallogr., 2011, 44, 1281.

16 L. J. Farrugia, J. Appl. Crystallogr., 2012, 45, 849.

17 K. Momma and F. Izumi, J. Appl. Crystallogr., 2011, 44, 1272.

18 V. A. Blatov, A. P. Shevchenko and D. M. Proserpio, Cryst. Growth Des., 2014, 14, 3576. 